\title{
Degradation Characteristics of Microstructure and Mechanical Properties for 9Cr-1MoVNb Steel aged under High-Temperature
}

\author{
K.H. JUNG AND S.J. KIM* \\ Mokpo National Maritime University, Division of Marine Engineering, Mokpo, Korea
}

\begin{abstract}
Thermal aging was conducted at $650^{\circ} \mathrm{C}$ until $1,000 \mathrm{~h}$ under the atmospheric environment to evaluate the degradation characteristics of microstructure and mechanical properties of $9 \mathrm{Cr}-1 \mathrm{MoVNb}$ steel. The analysis of the microstructure and carbide of aged specimens was conducted by scanning electron microscopy and energy dispersive X-ray spectroscopy. The mechanical properties were evaluated by tensile and Vickers hardness tests. In addition, fractured tensile specimens were characterized by using scanning electron microscopy and energy dispersive X-ray spectroscopy to observe the changes in fracture mode with aging time. As a result, loss of martensite lath, coarsening of $\mathrm{M}_{23} \mathrm{C}_{6}$ carbide, and precipitation of Laves phase were observed after aging for $100 \mathrm{~h}$. Degradation leads to deterioration in mechanical properties due to the effect of the nucleation and coarsening of Cr-rich $\mathrm{M}_{23} \mathrm{C}_{6}$ carbide. However, the change in fracture mode was more affected by the Laves phase $\left(\mathrm{Fe}_{2} \mathrm{Mo}\right)$ than the $\mathrm{M}_{23} \mathrm{C}_{6}$.
\end{abstract}

DOI: 10.12693/APhysPolA.135.994

PACS/topics: 9Cr-1MoVNb, high-temperature, degradation, microstructure, mechanical properties

\section{Introduction}

Since the 1980s, Cr-Mo tempered martensite steels have been widely used as materials such as tubes for steam generation and turbines of power generation and steam-propulsion vessels owing to the superior hightemperature strength, creep resistance, and oxidation resistance [1]. In addition, many shapes of Cr-Mo tempered martensite steels such as a tube $(\mathrm{T})$, pipe $(\mathrm{P})$, and plate specified in the ASTM and ASME have been popular in various industrial fields. In particular, since 9-12\% high alloy steels have superior strength and corrosion resistance at high temperatures than 1-2\% low alloy steel, it has been considered as a material that can satisfy the green energy requirements. The $9 \mathrm{Cr}-1 \mathrm{MoVNb}$ steels used in this study exhibit high creep strength owing to the dispersion effect of the $\mathrm{M}_{23} \mathrm{C}_{6}$ carbide and MX carbonitride [2]. $\mathrm{Mo}, \mathrm{Cr}, \mathrm{Mn}$, and $\mathrm{Fe}$ preferentially form $\mathrm{M}_{23} \mathrm{C}_{6}$ carbide at the boundaries of martensite lath and prior-austenite in the heat treatment process while $\mathrm{V}$, $\mathrm{Nb}$, and $\mathrm{N}$ form fine $\mathrm{MX}$ carbon nitride inside the matrix. $\mathrm{M}_{23} \mathrm{C}_{6}$ carbide and MX carbon nitride strengthen materials effectively as they play a role in pinning to prevent grain boundary sliding under static or tensile conditions [2]. Thus, alloy strength is strongly dependent on the number density and size of $\mathrm{M}_{23} \mathrm{C}_{6}$ carbide and MX carbonitride. However, the heat resistance steels suffer microstructure degradation due to the high temperature of the applied environment, which accelerated material aging. Accordingly, many studies have been conducted on corrosion, microstructural characteristics,

\footnotetext{
*corresponding author; e-mail: ksj@mmu.ac.kr
}

and strength of Cr-Mo steels under various applied environments. Lee at al. $[3,4]$ conducted a study on surface corrosion behaviors of T23 and T91 steels at $\mathrm{N}_{2}+\mathrm{H}_{2} \mathrm{~S}$ gas and atmospheric environments. Pandey et al. [5] conducted a study on creep resistance of cast-forged P91 steel at $620-650{ }^{\circ} \mathrm{C}$ and $120-200 \mathrm{MPa}$ conditions. The previous studies on $9 \mathrm{Cr}-1 \mathrm{MoVNb}$ steels have only focused on surface corrosion and creep strength when temperature and constant stress are simultaneously applied. However, few studies have been conducted on the evaluation of the mechanical strength of aged materials under pure high-temperature environments. In a previous study [6], the microstructural degradation of $9 \mathrm{Cr}-1 \mathrm{MoVNb}$ steel showed different characteristics depending on the stress. Thus, there is a somewhat limitation to predict degradation and strength characteristics of materials only through the high temperature creep strength. This study evaluated mechanical properties and fracture mode according to microstructural degradation of $9 \mathrm{Cr}-1 \mathrm{MoVNb}$ steel aged at pure high-temperature environments.

\section{Materials and equipment}

The chemical composition [wt. \%] of the $9 \mathrm{Cr}-1 \mathrm{MoVNb}$ steel used in this experiment is as follows: $0.1 \mathrm{C}, 0.38 \mathrm{Si}$, $0.46 \mathrm{Mn}, 0.25 \mathrm{Ni}, 8.38 \mathrm{Cr}, 0.93 \mathrm{Mo}, 0.18 \mathrm{~V}, 0.09 \mathrm{Nb}$, and the balance is Fe. The aging of the specimens was conducted for up to $1,000 \mathrm{~h}$ at $650^{\circ} \mathrm{C}$ under the atmosphere. The aged specimens were etched in tle Vilella reagent $(100 \mathrm{ml}$ ethanol, $1 \mathrm{~g}$ picric acid, and $5 \mathrm{ml} \mathrm{HCl})$ until the grain boundary was revealed, and then microstructure was characterized by SEM and EDS. The hardness was measured on the Vickers hardness tester at $9.807 \mathrm{~N}$ load and dwell time of $10 \mathrm{~s}$. This measurement was repeated seven times for each specimen to ensure the reproducibility. A mean value of hardness was calculated by five 
measurements except for the maximum and minimum values. The tensile test was conducted on the specimens with $6 \mathrm{~mm}$ width and $25 \mathrm{~mm}$ gauge length at room temperature through displacement control with $2 \mathrm{~mm} / \mathrm{min}$. After the tensile test, the fractured surface was observed through SEM and EDS.

\section{Results and discussion}

Figure 1 shows the microstructure of $9 \mathrm{Cr}-1 \mathrm{MoVNb}$ steel aged at $650{ }^{\circ} \mathrm{C}$ with time. The columnar lath and equiaxed lath existed complexly in the non-aged $9 \mathrm{Cr}-1 \mathrm{MoVNb}$ steel as shown in Fig. 1a, which shows a microstructure of typical tempered-martensite steel where coarse precipitates along the prior-austenite and lath boundary, and fine precipitates inside the matrix are uniformly distributed. However, the microstructure of $9 \mathrm{Cr}-1 \mathrm{MoVNb}$ steel exhibited distinct change with aging. As shown in Fig. $1 \mathrm{~b}-\mathrm{d}), \mathrm{M}_{23} \mathrm{C}_{6}$ carbides were precipitated and coarsened along the boundary of prioraustenite and martensite lath [7, 8]. In addition, a loss of martensite lath was observed due to the recombination of boundaries and expansion of the width from $100 \mathrm{~h} \mathrm{[9]}$. In the case of the specimen aged for $1000 \mathrm{~h}$, the boundary of martensite lath was observed unclearly as shown in Fig. 1d.
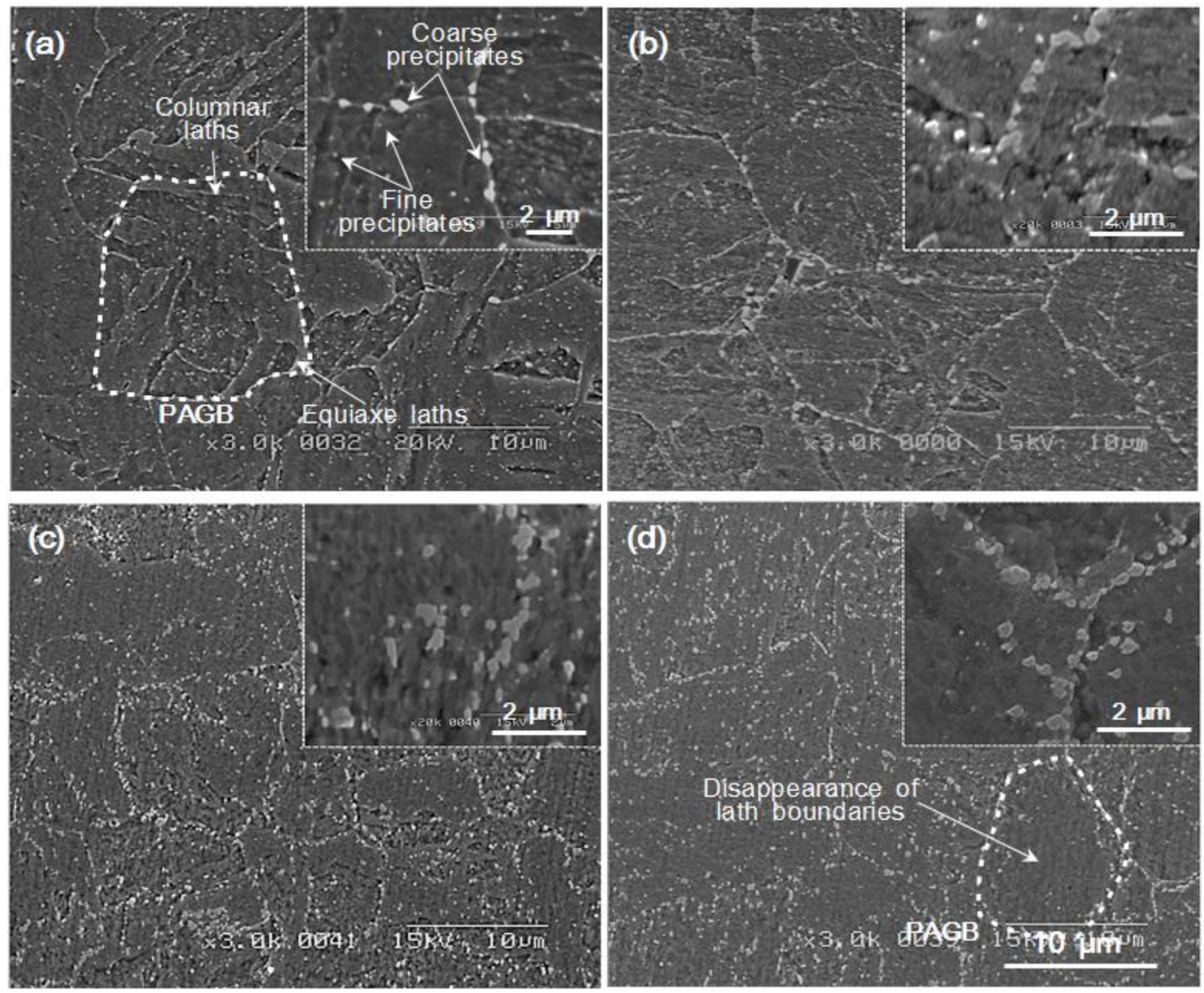

Fig. 1. Microstructure for $9 \mathrm{Cr}-1 \mathrm{MoVNb}$ steel aged at $650{ }^{\circ} \mathrm{C}$ with time, (a) non-aged, (b) $100 \mathrm{~h}$, (c) $500 \mathrm{~h},(\mathrm{~d}) 1,000 \mathrm{~h}$.

Figure 2 presents the EDS analysis results of $\mathrm{M}_{23} \mathrm{C}_{6}$ carbide and secondary phase of $9 \mathrm{Cr}-1 \mathrm{MoVNb}$ steel aged at $650{ }^{\circ} \mathrm{C}$ for $1,000 \mathrm{~h}$. The existence of an agglomerated zone of $\mathrm{Cr}$ and Mo inside the micro structure can be verified through the EDS element map (Fig. 2b, c). The EDS spot analysis results on the agglomerated
Cr zone showed that the Cr content was $16.30 \%$ (Fig. 2d), which was very high compared to that of the base metal. It means that the fine clusters precipitated at the austenite and lath grain boundaries were Cr-rich $\mathrm{M}_{23} \mathrm{C}_{6}$ carbide. The Mo content at the agglomerated zone that was exhibited in the Mo atom map was $12.77 \%$ (Fig. 2e), 

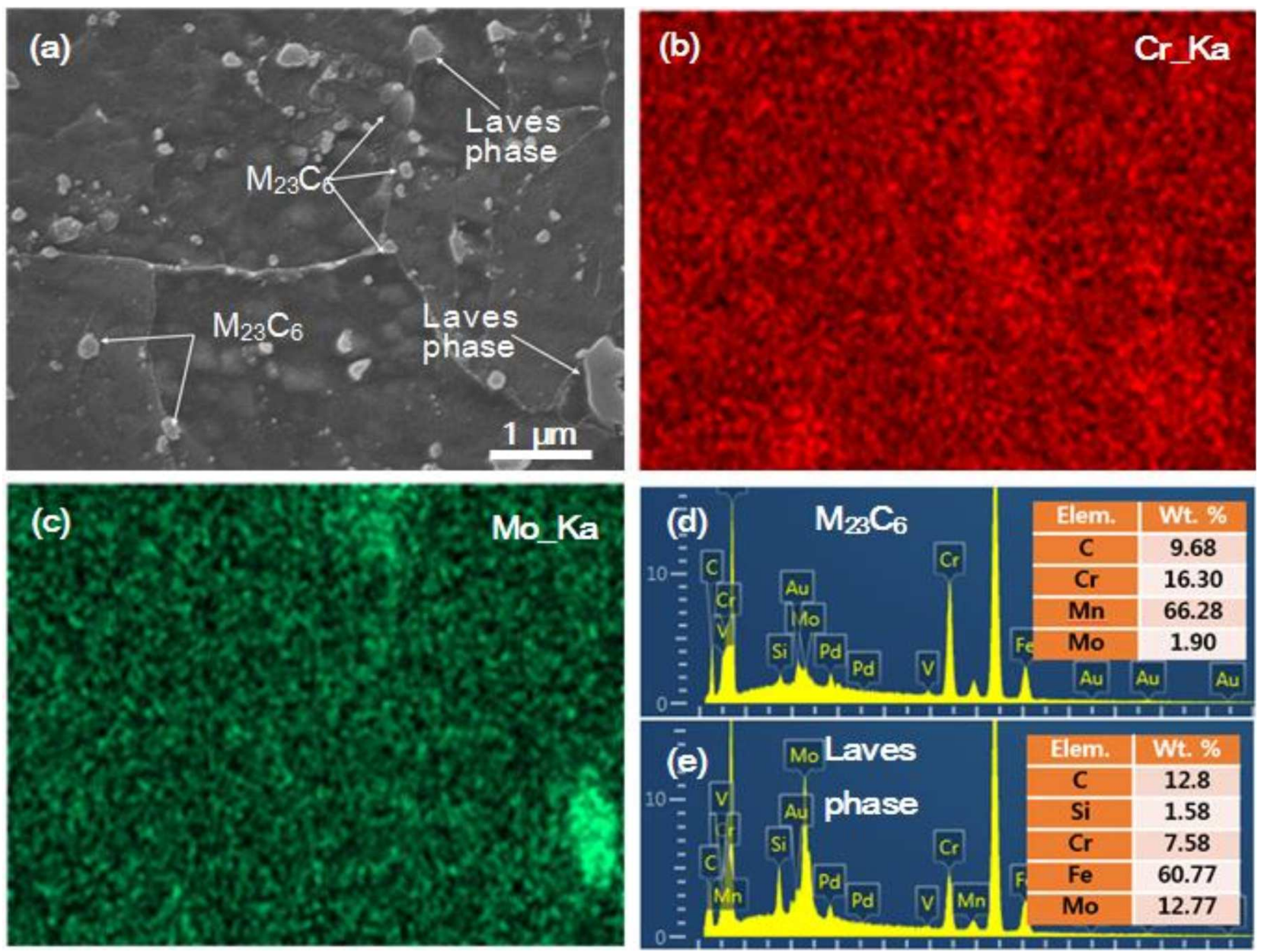

Fig. 2. EDS analysis for carbide of $9 \mathrm{Cr}-1 \mathrm{MoVNb}$ aged at $650^{\circ} \mathrm{C}$ during $1,000 \mathrm{~h}$, (a) surface morphology, (b) Cr elemental map, (c) Mo elemental map, (d) EDS spot results of $\mathrm{M}_{23} \mathrm{C}_{6}$, (e) EDS spot results of Laves phase.

which mean the precipitation of $\mathrm{Fe}_{2} \mathrm{Mo}$ Laves phase. $\mathrm{M}_{23} \mathrm{C}_{6}$ carbides enhance the materials by acting as an obstacle to the movement of the grain boundaries. In contrast, the Laves phase, which is the secondary phase of brittle, is quickly growing during high-temperature exposure [10]. Also, it contributed significantly to changes in fracture mode and strength degradation as it was acted as a cavity trigger under the tensile stress. As mentioned in the above, the secondary phase such as Laves phase and Cr-rich $\mathrm{M}_{23} \mathrm{C}_{6}$ carbide precipitated at the matrix and grain boundary was determined to affect the strength and fracture mode of the materials significantly.

Figure 3 depicts the mechanical properties of the aged $9 \mathrm{Cr}-1 \mathrm{MoVNb}$ steel (tension, yield, and elongation) with aging time. The mechanical properties of the $9 \mathrm{Cr}-1 \mathrm{MoVNb}$ steel were mainly affected by the expansion of martensite lath width, increase in precipitates at the prior-austenite grain boundary, decrease in transgranular fine carbides, and decrease in solid solution strengthening effect due to the secondary phase precipitation [11]. In particular, the $\mathrm{Cr}$-rich $\mathrm{M}_{23} \mathrm{C}_{6}$ carbides precipitated at grain boundary of the martensite lath and prior-austenite enhance the dispersion strengthening effect of metal.
On the other hand, the solid solution strengthening effect is weakened by the reduction of $\mathrm{Cr}$ concentration due to Cr-rich $\mathrm{M}_{23} \mathrm{C}_{6}$ carbide precipitation. The change in strength due to Cr-rich $\mathrm{M}_{23} \mathrm{C}_{6}$ carbide was complexly affected by the above two effects. Accordingly, the drastic decrease in tensile and yield strength at the initial $100 \mathrm{~h}$ was because the reduction in solid solution strengthening effect was more dominant as a result of the formation of Cr-rich carbides. Afterward, the two effects were acted equally over the aging time, and the behavior of degradation tended to be somewhat stagnated.

Figure 4 shows the Vickers hardness values of the aged $9 \mathrm{Cr}-1 \mathrm{MoVNb}$ steel with aging time. The hardness tends to decrease gradually up to $300 \mathrm{~h}$. Thereafter, the decrease in the hardness did not show any significant change with time. A study by Busby et al. [12] reported that there was a correlation between yield strength and hardness, and the degree is large enough to allow the hardness to be used as a measure of yield strength. In this study, yield strength and hardness value showed similar behavior. The above results showed that the reason for the degradation of hardness and yield strength was dominated by the same mechanism. Thus, it is considered 


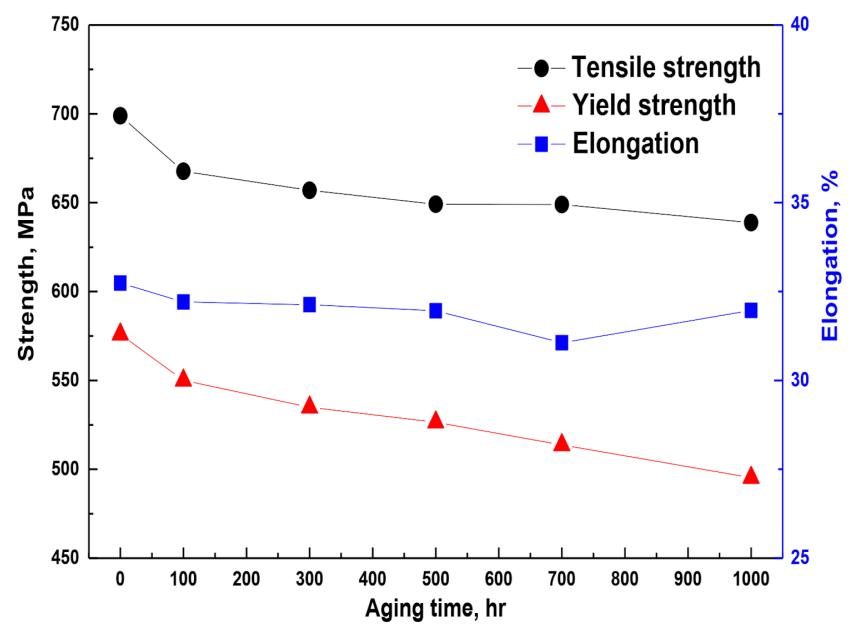

Fig. 3. Mechanical properties of $9 \mathrm{Cr}-1 \mathrm{MoVNb}$ steel aged at $650^{\circ} \mathrm{C}$ with time.

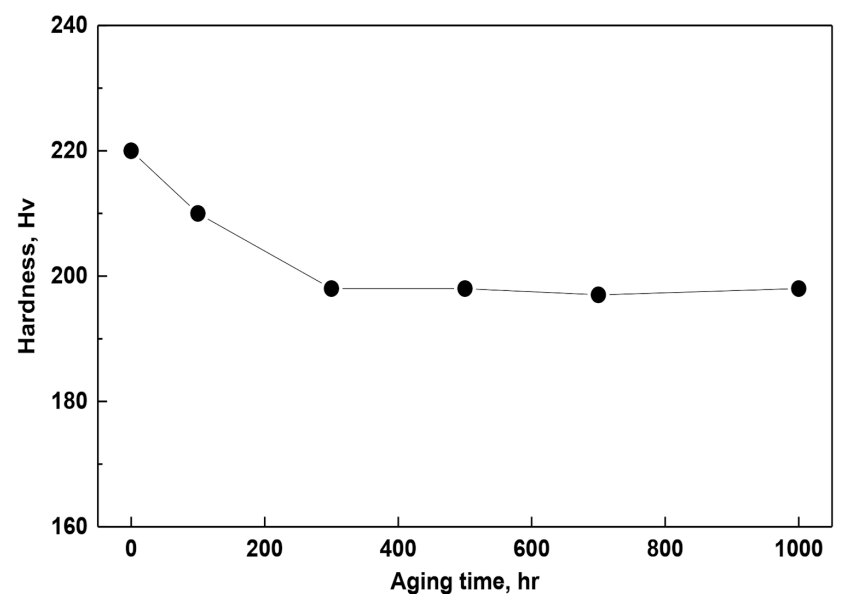

Fig. 4. Vickers hardness of $9 \mathrm{Cr}-1 \mathrm{MoVNb}$ steel aged at $650{ }^{\circ} \mathrm{C}$ with time.

that the degradation of hardness value was due to the effect of reduction of $\mathrm{Cr}$ concentration of the matrix by the precipitation of $\mathrm{Cr}$-rich $\mathrm{M}_{23} \mathrm{C}_{6}$ carbide.

Figure 5 describes the microstructure of the crosssection of fractured tensile specimens aged at $650{ }^{\circ} \mathrm{C}$. The microstructure was elongated to the load direction regardless of aging, and the boundaries of the prior-austenite and martensite lath were unclearly seen. A larger cavity around the precipitates was observed in the specimen aged for 1,000 $\mathrm{h}$ as shown in Fig. 5a than that of the specimen without aging as shown in Fig. 5b. This was because the second phase such as Laves phase and carbide precipitated in the martensite lath and the prior-austenite grain boundary was acting as nucleation of the crack and stress concentration under the tensile load. According to the study by Lee et al. [13], if a mean size of the second phase grew to $130 \mathrm{~nm}$ or larger, the brittleness of the material will be stronger. The secondary phases such as Laves phase and $\mathrm{Z}$ phase are rarely observed in non-aged materials in contrast with $\mathrm{M}_{23} \mathrm{C}_{6}$
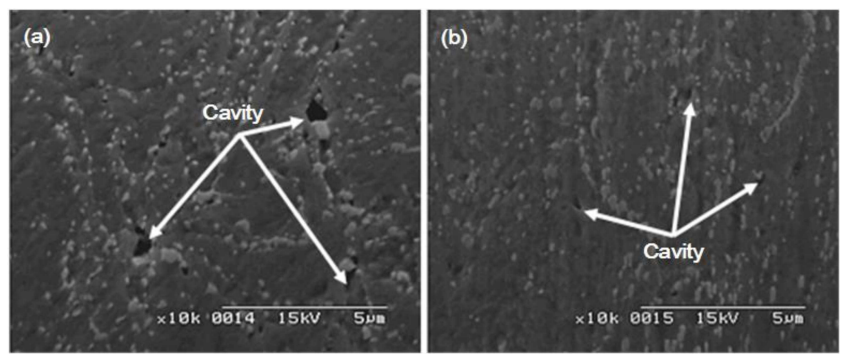

Fig. 5. Microstructure of fracture plane $9 \mathrm{Cr}-1 \mathrm{MoVNb}$ deteriorated at $650{ }^{\circ} \mathrm{C}$, a) non-aged, b) 1,000 h.

carbide and MX carbonitride. However, the nucleation and growth of them are progressed rapidly in a hightemperature environment (creep). A cavity was rarely observed in the base metal in Fig. 5b but cavities grew around the coarse precipitates of the aged specimen as shown in Fig. 5a. These cavities lead to a harmful effect on mechanical strength and failure mode of materials during the creep exposure.

Figure 6 presents the results of EDS analysis on the secondary phase around the cavities observed in Fig. 5a. The EDS spot analysis results verified that the second phase was the Laves phase observed in Fig. 2. Thus, most cavities were primarily formed around the coarse Laves phase of prior-austenite grain boundary and the martensite lath. Conclusively, the failure mode of the aged $9 \mathrm{Cr}-1 \mathrm{MoVNb}$ steel was strongly affected by the nucleation and growth of the Laves phase.

Figure 7 shows SEM images of the fracture surface for the $9 \mathrm{Cr}-1 \mathrm{MoVNb}$ steel aged at $650^{\circ} \mathrm{C}$ after the tensile test. The fractured surface exhibited "splitting" shape which has main cracks at the center of the specimen and secondary cracks around the surrounding area of the center regardless of the exposure time (Fig. $7 \mathrm{a}-\mathrm{c}$ ). The main cracks were perpendicular to the fracture direction of the material, meaning that cavity in the direction parallel to the tensile load, crack due to the coalescence of the cavity, and final fracture due to coalescence [14]. At the macro view, the secondary cracks around the main cracks tended to increase with the progress of aging time as shown in Fig. 7b, c. At the micro view,

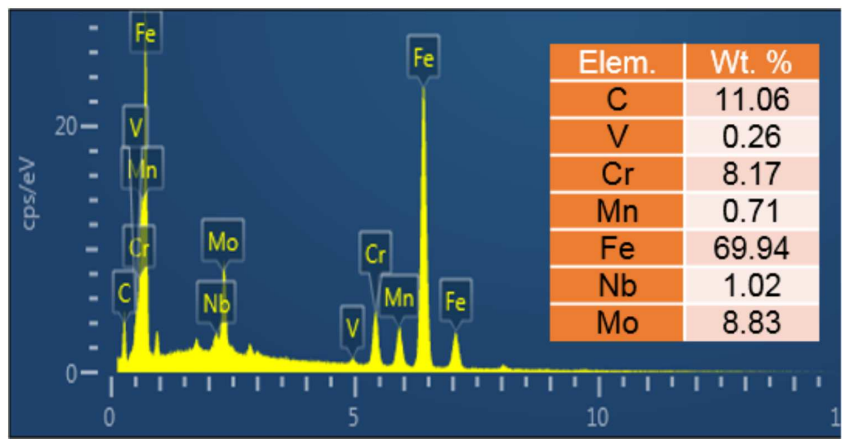

Fig. 6. EDS analysis for the secondar phase at fracture plane of $9 \mathrm{Cr}-1 \mathrm{MoVNb}$ steel aged at $650{ }^{\circ} \mathrm{C}$ during $1,000 \mathrm{~h}$. 

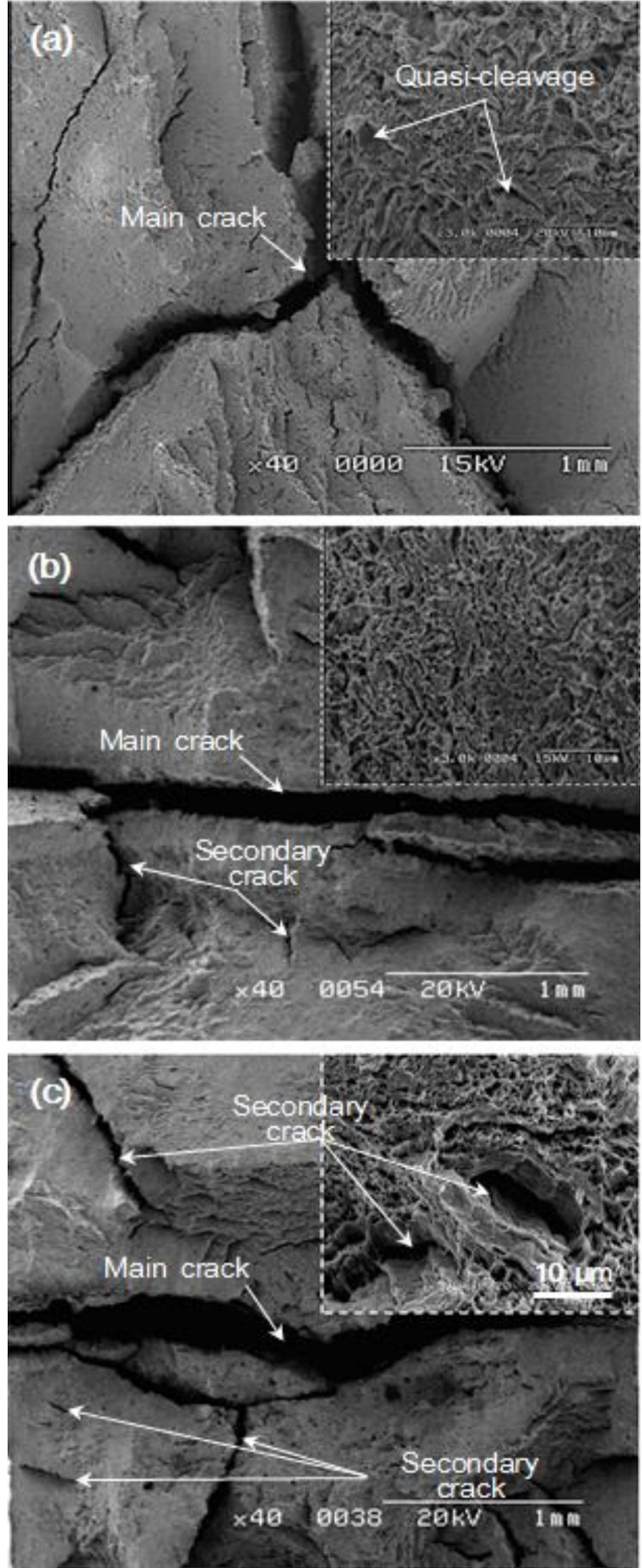

Fig. 7. Fractograph of $9 \mathrm{Cr}-1 \mathrm{MoVNb}$ steel aged at $650^{\circ} \mathrm{C}$ with time, (a) non-aged, (b) $100 \mathrm{~h}$, (c) $700 \mathrm{~h}$.

the fracture surface of the base metal (Fig. 7a) exhibited a fracture pattern where the transgranular dimple and quasi-cleavage plane were mixed. However, the fracture surface of the aged specimens exhibited secondary cracks with splitting type due to brittleness and decohesion. This was because the secondary phase and inclusions inside the metal were acted as nucleation of micro-cavities and cracks as shown in Figs. 5, 6. Thus, precipitation of the secondary phase was found a significant effect on the change in the fracture mode.

\section{Conclusion}

1. Microstructural degradation occurred with the progress of aging. The boundary of martensite lath was unclear, and coarse Cr-rich $\mathrm{M}_{23} \mathrm{C}_{6}$ carbide and Laves phase were precipitated at the boundary of prioraustenite and martensite lath.

2. The mechanical properties (tension, yield, and hardness) tended to decrease due to microstructural degradation such as a loss of martensite lath and coarsening of Cr-rich carbide.

3. The brittle and non-adhesive $\mathrm{Fe}_{2} \mathrm{Mo}$ Laves phase was acted as a cavity trigger under the tensile stress condition. The cavities were developed into the secondary cracks under the tensile stress, and the number of the secondary cracks tended to increase with the progress of aging. Thus, fracture mode of the aged $9 \mathrm{Cr}-1 \mathrm{MoVNb}$ steel was significantly affected by the Laves phase such as $\mathrm{Fe}_{2} \mathrm{Mo}$.

\section{Acknowledgments}

This research was a part of the project titled "Build a clean thermal power generation demonstration test bed, funded by 'the Ministry of Trade, Industry and Energy, Korea (No. 20161110100090).

\section{References}

[1] D.B. Lee, J. Kor. Inst. Surf. Eng. 49, 14 (2016).

[2] A.S. Khanna, High-Temperature Corrosion, World Scientific, Singapore 2016.

[3] D.B. Lee, M.A. Abro, P. Yadav, S.H. Bak, Y. Shi, M.J. Kim, J. Kor. Inst. Surf. Eng. 49, 147 (2016).

[4] D.B. Lee, S.H. Bak, J. Kor. Inst. Surf. Eng. 49, 339 (2016).

[5] C. Pandey, M.M. Mahapatra, P. Kumar, R.S. Vidyrathy, A. Srivastava, Mater. Sci. Eng. A 695, 291 (2017).

[6] K. Kimura, K. Sawada, H. Kushima, K. Kubo, Int. J. Mat. Res. 99, 395 (2008).

[7] S. Spigarelli, Int. J. Press. Vessels Piping 101, 64 (2013).

[8] C. Pandey, M.M. Mahapatra, J. Mater. Eng. Perform. 25, 2195 (2016).

[9] F. Abe, Mater. Sci. Eng. A 384, 565 (2004).

[10] C.G. Panait, W. Bendick, A. Fuchsmann, A.F. Gourgues-Lorenzon, J. Besson, Int. J. Press. Vessels and Piping 87, 326 (2010).

[11] K. Sawada, M. Takeda, K. Maruyama, R. Ishii, M. Yamada, Y. Nagae, R. Komine, Mater. Sci. Eng. A 267, 19 (1999).

[12] J.T. Busby, M.C. Hash, G.S. Was, J. Nucl. Mater. 336, 267 (2005).

[13] J.S. Lee, H.G. Armaki, K. Maruyama, Mater. Sci. Eng. A 428, 270 (2016).

[14] C. Pandey, N. Saini, M.M. Mahapatra, P. Kumar, Eng. Fail. Anal. 71, 131 (2017). 